\title{
Endogenous peptide ligand-receptor systems for diverse signaling networks in plants
}

\author{
Satoshi Endo ${ }^{1}$, \\ Shigeyuki Betsuyaku ${ }^{1,2}$ and \\ Hiroo Fukuda ${ }^{1}$
}

\section{Addresses}

${ }^{1}$ Department of Biological Sciences, Graduate School of Science, The

University of Tokyo, 7-3-1 Hongo, Bunkyo-ku, Tokyo 113-0033, Japan

${ }^{2}$ PRESTO, Japan Science and Technology Agency (JST), 4-1-8 Honcho, Kawaguchi, Saitama 332-0012, Japan

Corresponding authors:

Endo, Satoshi (satoshi@bs.s.u-tokyo.ac.jp)

Fukuda, Hiroo (fukuda@bs.s.u-tokyo.ac.jp)

\section{Word count}

Abstract: 108

Text: 2480 
Endogenous peptide ligand-receptor systems regulate cell-cell communications in various developmental processes in plants. Recent studies have revealed that the peptide-receptor combinations are not simply one-on-one with single roles. One peptide activates multiple downstream signaling through different receptors, while one receptor transmits different signals depending on peptide partners. Peptide signaling pathways also crosstalk with signaling pathways of phytohormones such as auxin, cytokinin and brassinosteroids. Furthermore, environmental cues such as temperature, nutrient, and microbes activate or inactivate peptide signaling pathways, which in turn modulate developmental processes. This report summarizes recent advance on peptide-receptor signaling, which makes a signaling network with phytohormone signaling pathways and environmental responses.

\section{Highlights}

- A range of ligand specificity of receptors allows complex peptide-receptor combinations.

- $\quad$ Peptides and phytohormones make signaling networks.

- Peptide signaling mediates environmental responses to modulate developmental processes. 


\section{Introduction}

During evolution, plants have tremendously increased genes encoding peptide ligands and receptors, which are required for highly orchestrated cell-cell communications [1]. Plant peptide ligands can be grouped into two types [2]: small post-translationally processed peptides such as CLAVATA3 (CLV3)/ESR-related (CLE) peptides [3] and Pep peptides [4], and cysteine-rich peptides such as LURE [5] and Stomagen [6,7]. It is commonly believed that these peptide ligands are secreted from cells and then received by the extracellular domains of transmembrane-type receptor kinases in other cells, triggering changes in the phosphorylation state of downstream components to transmit signals. The Arabidopsis thaliana genome is predicted to possess over 1000 potential peptide ligands and over 600 receptors [8]. Although a tremendously large number of ligand-receptor pairings are possible amongst them, only a few peptide-receptor combinations have been identified and assigned to specific biological functions (Table 1). Nevertheless, such small examples are sufficient to convince us that the relationship between ligands and receptors are not in a simple one-on-one relation but highly complicated $\left[9^{\bullet \bullet}, 10^{\bullet \bullet}-12^{\bullet}-16^{\bullet}-18\right]$. In this review, we do not go deeper in this complexity since the details has been described comprehensively [2,19]. Instead, we do more focus on recent findings that related peptide functions either to phytohormone signaling pathways $\left[9^{\bullet \bullet}, 10^{\bullet \bullet}, 20-22\right]$ or to environmental responses $\left[13,23^{\bullet \bullet}, 24^{\bullet \bullet}-29\right]$. Hence, we here summarize recently discovered combinations of peptides and receptors, with an emphasis on the crosstalk of peptide signaling pathways with other peptide 
signaling pathways, phytohormone signaling pathways and environmental cues.

\section{The complexity in peptide-receptor modules}

Recent studies have revealed that combinations of peptides and receptors are not one-on-one with single roles. In the simplest case, a peptide-receptor module used for a developmental process is recruited into another developmental process (Figure 1a). A CLE peptide-receptor module consisting of TRACHEARY ELEMENTS INHIBITORY FACTOR (TDIF) and TDIF RECEPTOR (TDR) is well known to function in the maintenance of vascular stem cells [30]. A recent study indicates that this module directly regulates the activity of glycogen synthase kinase 3 (GSK3) family proteins including BRASSINOSTEROID-INSENSITIVE2 (BIN2), to maintain vascular stem

cells $\left[9^{\bullet \bullet}\right]$. Interestingly, Cho and others found that the same module, TDIF-TDR-BIN2 is involved in lateral root formation in the pericycle $\left[10^{\bullet \bullet}\right]$.

In the second case, one peptide ligand generates multiple signals through multiple receptors to function in different developmental processes (Figure 1b).

INFLORESCENCE DEFICIENT IN ABSCISSION (IDA) peptide functions through the redundant activities of HAESA (HAE) and HAESA-LIKE2 (HSL2) receptors in floral organ abscission. The same module is used in lateral root elongation to remove overlayering endodermal, cortical and epidermal cells [11]. However, detailed genetic and phenotypic analyses of hae and $h s l 2$ mutants suggested that IDA-HAE and IDA- 
HSL2 function in slightly different aspects during lateral root elongation, because both hae and $h s l 2$ mutants exhibit a phenotype of delayed lateral root emergence and they show different expression patterns of genes for cell wall-modifying enzymes associated with cell clearance [11].

The third case is that multiple peptide ligands generate different signals through a single receptor (Figure 1c). CVL1 receptor perceives CLV3 peptide in relation to shoot meristem maintenance and also CLE40 peptide in root meristem maintenance [12 $\left.{ }^{\bullet}\right]$. Misexpression and promoter swap experiments have indicated that CLV3 and CLE40 are functionally equivalent proteins that differ mainly in their expression patterns [31]. In addition, CLE3 peptide was found to utilize the CLV1 activity in regulating lateral root formation [13]. It would be a next challenge to dissect whether CLE3 and CLV3 are also functionally equivalent in lateral root formation.

In the above cases, the biological activities of individual peptide-receptor pairs are mainly defined by tissue-specific expression patterns of the pairs. A peptide-receptor pair can function in different developmental contexts in different tissues. An example of IDA-HAE/HSL2 modules indicates that the tissue specificity can also differentiate biological outputs of ligand-receptor modules in a tissue, which are redundant in another tissue. In addition, differentially expressed ligands act on a receptor in different developmental events as seen in CLV3/CLE40/CLE3-CLV1 combination. The affinity between a peptide-receptor pair, however, might provide another level of specification of peptide-receptor functions. CLE9 peptide binding was first identified for BARLEY 
ANY MERISTEM1 (BAM1) receptor, while CLE9 peptide also bound to BAM2, BAM3 as well as CLV1 [14]. Interestingly, CLE9 exhibited differential affinity against these receptors. In addition, BAM1 showed high binding affinity to not only CLE9 but also all of CLE8-CLE14 peptides, a CLE subfamily that CLE9 peptide belongs to. Thus, various levels of specificity contribute to 'specific' functions of peptide-receptor pairs. Further complexity is also seen in cysteine-rich peptide-receptor modules. Stomatal cell fates are regulated by signaling pathways consisting of three similar cysteine-rich peptides EPIDERMAL PATTERNING FACTOR1 (EPF1), EPF2 and Stomagen and receptor complexes of a receptor-like protein, TOO MANY MOUTHS (TMM) and ERECTA (ER) family proteins: ER, ER-LIKE1 (ERL1) and ERL2 [15]. A genetic analysis with dominant-negative mutants of ER and ERL1 suggested that EPF1-ERL1 and EPF2-ER pairs function in stomatal spacing and stomatal cell lineage initiation, respectively $\left[16^{\bullet \bullet}\right.$ ]. ER and $E R L 1$ are also expressed in phloem, in which they function redundantly in maintaining vascular stem cells with other related peptides, EPF-LIKE4 (EPFL4) and EPFL6 [17]. In contrast, only ER is involved in EPFL4/EPFL6-mediated stem elongation [18]. Thus ER family proteins perceive a range of peptides and transmit multiple signals to regulate different developmental processes.

\section{Integration of peptide signaling and phytohormone signaling}

Recent advance in studies of peptide functions has revealed the close interaction 
between phytohormones and peptides in developmental aspects. Cytokinin inhibits protoxylem vessel formation in roots [32]. In Arabidopsis roots, treatment with CLE10 peptide inhibits protoxylem vessel formation and specifically reduces expression of type-A ARABIDOPSIS RESPONSE REGULATORs (ARRs), which are known as negative regulators of cytokinin signaling, in particular ARR5 and ARR6 [20]. Indeed, in arr5 arr6 roots, protoxylem vessel formation is often inhibited. In contrast, ectopic protoxylem vessels are formed in arr10 arr12, a double mutant for two type-B ARRs, which function positively in cytokinin signaling. Thus, CLE10 peptide activates cytokinin signaling through the repression of $A R R 5$ and $A R R 6$, resulting in inhibition of protoxylem vessel formation. Genetic analysis has suggested the involvement of CLV2 receptor-like protein in CLE10 peptide signaling [20].

GSK3/SHAGGY-like kinases are key players of various signaling pathways in plants as well as animals, fungi and amoebae [33]. Recent studies have revealed that plant GSK3 proteins connect peptide signaling with phytohormone signaling. In Arabidopsis, there are 10 members of GSK3s, consisting of four subgroups SKI-IV. BIN2, BIN2-LIKE1 (BIL1) and BIL2, which belong to SKII, are well known to mediate brassinosteroid (BR) signaling [33]. In stomatal formation, a transcription factor SPEECHLESS $(\mathrm{SPCH})$ promotes the differentiation of leaf epidermal cells into the stomatal lineage. As shown above, EPF1, EPF2 and Stomagen peptides interact with complexes composed of TMM and ER family receptors. ER regulates the stability of SPCH through mitogen-activated protein (MAP) kinase signaling [34]. Recently BIN2, BIL1 and BIL2, which acts downstream of BR, are implicated in redundantly 
modulating the stability of SPCH by directly or indirectly affecting phosphorylation of SPCH [21,22].

Another example of interaction between BR and a peptide through GSK3s is seen in xylem vessel formation from procambial cells $\left[9^{\bullet \bullet}\right.$ ]. TDIF suppresses the differentiation of procambial cells into xylem cells, while BR promotes xylem cell differentiation [35]. Kondo and others indicated that all SKI and II members interact with TDR at the plasma membrane in plant cells, and their interactions are regulated in a TDIF-dependent manner $\left[9^{\bullet \bullet}\right]$. Genetic analysis revealed that these GSK3s redundantly mediate TDIF-TDR signaling to suppress xylem differentiation. In this pathway, BRI1-EMS SUPPRESSOR1 (BES1) but not BRASSINAZOLE RESISTANT 1 (BZR1) functioned as a downstream factor of the GSK3s. These results suggest that TDIF and BR signals regulate GSK3s activity as 'ON' and 'OFF' inputs, to determine whether the procambium differentiates into the xylem. The TDIF-TDR-GSK3s module also interacts with auxin signaling. In lateral root formation, TDIF-TDR activates BIN2, which in turn, phosphorylates AUXIN RESPONSE FACTOR7 (ARF7) and ARF19 in pericycle cells $\left[10^{\bullet \bullet}\right.$ ]. This TDIF-TDR-BIN2-dependent modulation of auxin signaling promotes lateral root formation. In this process, intriguingly, BR signaling does not appear to have major impact on the regulation of BIN2 activity.

\section{Environmental responses}


Plant developmental processes are affected by various environmental factors due to the sessile lifestyle of plants. CLE peptide signaling systems have been implicated to be crucial only for internal developmental processes including meristem maintenance [3]. However, recent studies have revealed new CLE peptides mediating environmental cues: CLE45 peptide was first discovered as a peptide that alleviates growth defect of pollen tubes at $30^{\circ} \mathrm{C}$ in vitro $\left[23^{\bullet \bullet}\right.$. In situ, CLE45 expression was induced in the transmitting tract of pistils by moderately high temperature treatment $\left(30^{\circ} \mathrm{C}\right)$, but not at normal temperature $\left(22^{\circ} \mathrm{C}\right)$. The receptors for CLE45 peptide were identified as STERILITY-REGULATING KINASE MEMBER1 (SKM1) and SKM2. SKM1 and SKM2 are expressed preferentially in pollen and pollen tubes regardless of temperature. Further analysis revealed that CLE45-SKM1/SKM2 signaling is responsible for the male-female cell interaction through alleviating heat stress in pollen, leading to successful fertilization. Interestingly, CLE45 was also expressed in phloem cells. Another CLE45 signaling is also implicated in vascular development, because CLE45 peptide application inhibited protophloem differentiation in a BAM3-dependent manner in roots [36].

It is well known that root growth is affected by the amount of nutrients, such as nitrogen, ammonium, nitrate and phosphate in soil. Recent studies have revealed that CLE peptide signals mediate between nitrate and root growth. Lateral roots stop growing with severe deficiency of nitrate. The expression of CLE3 gene was induced in pericycle cells in response to nitrate deficiency [13]. The own promoter-based CLE3 overexpression suppressed the lateral root growth in a manner dependent on $C L V 1$, 
which is expressed in companion cells. CLV3-CLV1 signaling is a well-known crucial system for regulating apical shoot meristem maintenance [37]. However, this finding indicated that CLE3-CLV1 signaling also acts at nitrate sensing to control lateral root growth. In addition, two Lotus japonicus CLE genes, LjCLE19 and LjCLE20, have been reported to be induced by the presence of phosphate in roots [38]. The root system is a tissue providing mechanical support for the aerial part of a plant body as well as a structure directly contacting soil where the plant uptakes water and nutrients. Thus, development of the root system needs to be highly coordinated with the environmental conditions. Considering the well-known activities of the CLE genes in developmental regulation, the CLE family might function to integrate environmental information into the regulation of plant development.

The CLE family is also implicated in symbiotic interaction between rhizobia and legumes. Autoregulation of nodulation in legume roots is associated with leucine-rich repeat (LRR) type receptors such as HYPERNODULATION ABBERANT ROOT FORMATION1 (HAR1) and KLAVIER [39]. Recently LjCLE-RS2 peptide, which was modified with three arabinose moieties, was demonstrated to be a signaling molecule for HAR1 in L. japonicus $\left[24^{\bullet \bullet}\right.$ ]. LjCLE-RS2 peptide is produced in roots and transported to shoots. This finding clearly indicates that a CLE peptide-receptor system is responsible for a long distance signaling. Interestingly, $L j C L E-R S 2$ expression was induced in response to excess nitrate to negatively regulate nodulation [40]. The amount of nitrogen in soil is a key factor of nodule development and function [40]. Because Lotus LjCLE-RS2 is quite close to Arabidopsis CLE3, the legume plant may develop a 
system to regulate symbiotic nodulation through a nitrate-sensing mechanism involving the CLE3-type peptide [41].

Pep peptide is known to function in biotic stress response. Recently, a few groups simultaneously reported that Pep peptide-PEPR1/PEPR2 receptor signaling amplifies innate immunity by producing a positive feedback loop together with ethylene [25-27]. Phytosulfokine- $\alpha$ (PSK- $\alpha$ ) and PSY1 (plant peptide containing sulfated tyrosine 1) are tyrosine-sulfated peptides and function in cell proliferation and expansion through specific LRR-receptor kinases. In addition, these modules are also integrated in plant defense responses $[28,29]$. General regulators such as PSK family signaling may be involved in various plant responses including defense responses for adjusting cell growth.

\section{Conclusions and perspectives}

Figure 2 illustrates the above mentioned interactions of peptide signaling toward various cellular processes. Clearly, peptides, receptors and downstream factors form a network together with phytohormone signaling pathways and biotic and abiotic responses. As we discussed above, there are a few homologs in both peptides and receptors. Their tissue specific expression patterns are the first keys to discriminate the function of peptide-receptor pairs. Different affinities in homologous peptide-receptor pairs might serve as another level of specificity. To understand the complicated mechanisms of peptide 
signaling, we should reveal the cross points of the signaling at the molecular basis. Phosphoproteomics may be a powerful tool to detect a key factor involved in intracellular signaling pathways initiated by a peptide ligand $\left[42^{\circ}\right]$. Live imaging of peptide signaling is also important for understanding actual signaling in cells. Identification of receptor complexes using multiparameter fluorescence image spectroscopy is promising $\left[12^{\circ}\right]$. Development of fluorescence labeling technology for small peptides is a next great challenge. Recently Song and others found that substitution of Gly to Thr in CLE domain produced antagonistic CLE8 and CLV3 peptides [43]. Antagonistic peptides may also be able to overcome functional redundancy of CLE peptides.

Recent studies on peptide-receptor combinations emphasize that plant endogenous peptides, which were hitherto believed to act only in endogenous developmental processes such as meristem maintenance, are also regulated by various environmental cues. We do not yet know endogenous functions for most of the peptides and receptors. One might explain that such a complexity might contribute to fine-tuning of detailed morphogenesis, or may point to the importance of functional redundancy among them to ensure proper development. We, however, emphasize another possibility that peptide-receptor systems might serve as integrators of environmental information into developmental regulation of plants. In this view, the presence of many peptide and receptor genes, for example, may be required for sensing different environmental conditions in different tissues. Thus, plants may achieve developmental plasticity in response to the environment using a great repertory of peptide-receptor pairs in a 
context dependent manner. The peptide-receptor environmental sensors might modulate phytohormone-driven developmental process upon environmental stimuli. It might be extremely difficult to analyze individual environmental factors in the uniformly controlled growth condition of a laboratory. However, a recent advance in the analysis of complex transcriptome data sets obtained from rice grown in paddy-field in combination with the corresponding meteorological data succeeded not only to dissect complex and noisy environmental factors in relation to transcriptional responses but also to predict plant responses in given conditions [44]. Using fluctuating conditions in the open air to dissect environmental stimuli, such a large-scale statistical analysis focusing on genes encoding peptide ligands would advance our understanding of peptide-receptor pair functions, especially in terms of morphological plasticity that can only be detectable in plants growing under the real open air conditions where they normally survive.

\section{Acknowledgement}

We thank Dr. Yuki Kondo for his valuable comments on this article. This work was supported partly by Grants-in-Aid from the Ministry of Education, Science, Sports and Culture of Japan (NC-CARP project) to HF and SE, and from the Japan Society for the Promotion of Science (23227001 to HF). This work was also supported partly by Japan Science and Technology Agency (JST), Precursory Research for Embryonic Science and Technology (PRESTO) (to SB). 


\section{Figure legends}

\section{Figure 1}

The complexity in peptide-receptor modules.

(a) TDIF-TDR; (b) IDA-HAE/HSL2; (c) CLV3/CLE40/CLE3-CLV1. See the text.

\section{Figure 2}

A schematic network of peptide-receptor signaling, phytohormone signaling, and environmental cues.

Signaling components described in the text are shown in interconnection with environmental cues and developmental processes. Green circles and neighboring blue pentagons with blue lines indicate peptide-receptor signaling. Red squares, hexagons and lines indicate phytohormone signaling. Black squares with black lines are environmental cues and responses. Gray lines indicate multiple interactions. Gray squares indicate associated biological contexts. 
Table 1

Identified plant peptide ligands-receptor combinations

\begin{tabular}{|c|c|c|}
\hline Peptide (type) & Receptor (type) & Reference \\
\hline $\mathrm{CLV}^{\mathrm{a}}$ (small) & $\mathrm{CLV}^{\mathrm{a}}{ }^{\mathrm{a}}$ (LRR class XI), CLV2 ${ }^{\mathrm{a}}$ (RLP), RPK2/TOAD2 (LRR) & {$[37,45,46]$} \\
\hline CLE3 (small) & CLV1 (LRR class XI) & [13] \\
\hline CLE8, 9/10, 11, 12, 13, 14 (small) & BAM1 (LRR class XI) & [14] \\
\hline CLE9 $^{\text {a }}$ (small) & $\mathrm{BAM}^{\mathrm{a}}, \mathrm{BAM}^{\mathrm{a}}{ }^{\mathrm{a}}, \mathrm{BAM} 3^{\mathrm{a}}, \mathrm{CLV} 1^{\mathrm{a}}$ (LRR class XI) & [14] \\
\hline CLE10 (small) & CLV2 (RLP) & [20] \\
\hline CLE40 (small) & ACR4 (CR4L), CLV1 (LRR class XI) & {$\left[12^{\bullet}\right]$} \\
\hline CLE41/TDIF ${ }^{\mathrm{a}}$ (small) & TDR/PXY ${ }^{\mathrm{a}}$ (LRR class XI) & [30] \\
\hline CLE45 ${ }^{\mathrm{a}}$ (small) & BAM3, SKM1 ${ }^{\mathrm{a}}$, SKM2 (LRR class XI) & {$\left[23^{\bullet \bullet}, 36\right]$} \\
\hline FON2 (small) & FON1 (LRR class XI) & [47] \\
\hline LjCLE-RS1 $^{\text {a }}$, LjCLE-RS2 ${ }^{\mathrm{a}}$ (small) & HAR $1^{\mathrm{a}}$ (LRR class XI) & {$\left[24^{\bullet \bullet}\right]$} \\
\hline MtCLE12, MtCLE13 (small) & SUNN (LRR class XI) & [48] \\
\hline GmRIC1, GmRIC2, GmNIC1 (small) & GmNARK (LRR class XI) & [49] \\
\hline Pep1 ${ }^{\mathrm{a}}$, Pep2 ${ }^{\mathrm{a}}$ (small) & PEPR $^{a}$, PEPR2 ${ }^{\mathrm{a}}$ (LRR class XI) & [4] \\
\hline PSK- $\alpha^{\mathrm{a}}$ (small) & $\operatorname{PSKR}^{\mathrm{a}}($ LRR class $\mathrm{X})$ & [50] \\
\hline PSY1 (small) & PSY1R (LRR class X) & [51] \\
\hline RALF $^{\text {a }}$ (Cys-rich) & FER $^{\mathrm{a}}(\mathrm{CrRLK} 1 \mathrm{~L})$ & {$\left[42^{\bullet}\right]$} \\
\hline IDA, IDLs (small) & HAE, HSL2 (LRR class XI) & [52] \\
\hline $\mathrm{EPF} 1^{\mathrm{a}}$ (Cys-rich) & $\mathrm{ER}^{\mathrm{a}}, \mathrm{ERL1}^{\mathrm{a}}(\mathrm{LRR}$ class XIII) & {$\left[16^{\bullet \bullet}\right]$} \\
\hline $\mathrm{EPF}^{\mathrm{a}}$ (Cys-rich) & $\mathrm{ER}^{\mathrm{a}}, \mathrm{ERL1}^{\mathrm{a}}\left(\mathrm{LRR}\right.$ class XIII), $\mathrm{TMM}^{\mathrm{a}}(\mathrm{RLP})$ & {$\left[16^{\bullet \bullet}\right]$} \\
\hline EPFL4 $^{\text {a }}$, EPFL6/CHALLAH ${ }^{\text {a }}$ (Cys-rich) & $\mathrm{ER}^{\mathrm{a}}, \mathrm{ERL1}$ (LRR class XIII) & {$[17,18]$} \\
\hline Stomagen/EPFL9 (Cys-rich) & TMM (RLP) & {$[6,7]$} \\
\hline SP11/SCR ${ }^{\mathrm{a}}$ (Cys-rich) & SRK $^{\mathrm{a}}$ (S-domain) & [53] \\
\hline TPD1 (Cys-rich) & EMS1 (LRR class X) & [54] \\
\hline
\end{tabular}

${ }^{\mathrm{a}}$ Direct binding was shown. LRR, leucine-rich repeat; RLP, receptor-like protein; CR4L, CRINKLY4-like; CrRLK1L, Catharanthus roseus RLK1-like kinase. 


\section{References and recommended reading}

Papers of particular interest, published within the annual period of review, have been highlighted as:

- of special interest

- of outstanding interest

1. Shiu SH, Bleecker AB: Receptor-like kinases from Arabidopsis form a monophyletic gene family related to animal receptor kinases. Proc Natl Acad Sci U S A 2001, 98:10763-10768.

2. Matsubayashi Y: Post-translational modifications in secreted peptide hormones in plants. Plant Cell Physiol 2011 52:5-13.

3. Betsuyaku S, Sawa S, Yamada M: The function of the CLE peptides in plant development and plant-microbe interactions. The Arabidopsis book 2011, 9:e0149.

4. Yamaguchi Y, Huffaker A, Bryan AC, Tax FE, Ryan CA: PEPR2 is a second receptor for the Pep1 and Pep2 peptides and contributes to defense responses in Arabidopsis. Plant Cell 2010, 22:508-522. 
5. Okuda S, Tsutsui H, Shiina K, Sprunck S, Takeuchi H, Yui R, Kasahara RD, Hamamura Y, Mizukami A, Susaki D et al.: Defensin-like polypeptide LUREs are pollen tube attractants secreted from synergid cells. Nature 2009, 458:357-361.

6. Sugano SS, Shimada T, Imai Y, Okawa K, Tamai A, Mori M, Hara-Nishimura I: Stomagen positively regulates stomatal density in Arabidopsis. Nature 2010, 463:241-244.

7. Kondo T, Kajita R, Miyazaki A, Hokoyama M, Nakamura-Miura T, Mizuno S, Masuda Y, Ire K, Tanaka Y, Takada S et al.: Stomatal density is controlled by a mesophyll-derived signaling molecule. Plant Cell Physiol 2010, 51:1-8.

8. Czyzewicz N, Yue K, Beeckman T, De Smet I: Message in a bottle: small signalling peptide outputs during growth and development. J Exp Bot 2013, 64:5281-5296.

9. Kondo Y, Ito T, Nakagami H, Hirakawa Y, Satito M, Tamaki T, Shirasu K, Fukuda H: Plant GSK3 proteins regulate xylem cell differentiation downstream of TDIF-TDR signalling. Nat Commun 2014, 5:3504.

This study clearly showed the direct interaction of TDR with BIN2 in a 
TDIF-dependent manner. The control of GSK3 proteins including BIN2 was found to be critical for the determination of xylem differentiation.

10. Cho H, Ryu H, Rho S, Hill K, Smith S, Audenaert D, Park J, Han S, Beeckman T, Bennett M et al.: A secreted peptide acts on BIN2-mediated phosphorylation of ARFs to potentiate auxin response during lateral root development. Nat Cell Biol 2014, 16:66-76.

This article clearly showed that the direct interaction of BIN2 with ARF7/19 regulated lateral root development. TDR interacted with BIN2 in the pericycle. Auxin and TDIF signaling governed the lateral root formation but less likely by brassinosteroid.

11. Kumpf RP, Shi C-L, Larrieu A, Stø IM, Butenko MA, Péret B, Riiser ES, Bennett MJ, Aalen RB: Floral organ abscission peptide IDA and its HAE/HSL2 receptors control cell separation during lateral root emergence. Proc Natl Acad Sci U S A 2013, 110:5235-5240.

12. Stahl Y, Grabowski S, Bleckmann A, Kühnemuth R, Weidtkamp-Peters S, Pinto KG, Kirschner GK, Schmid JB, Wink RH, Hülsewede A et al.: Moderation of Arabidopsis root stemness by CLAVATA1 and ARABIDOPSIS CRINKLY4 receptor kinase complexes. Curr Biol 2013, 23:362-371. 
This article showed that CLV1 was also required in root meristem maintenance as for shoot. CLV1 and formerly identified ACR4 receptors interacted with each other and perceived CLE40 peptide. Differences in intracellular localization of homo- and heteromeric receptor complexes of CLV1 and ACR4 were shown using multiparameter fluorescence image spectroscopy.

13. Araya T, Miyamoto M, Wibowo J, Suzuki A, Kojima S, Tsuchiya YN, Sawa S, Fukuda H, von Wirén N, Takahashi H: CLE-CLAVATA1 peptide-receptor signaling module regulates the expansion of plant root systems in a nitrogen-dependent manner. Proc Natl Acad Sci U S A 2014, 111:2029-2034.

14. Shinohara H, Moriyama Y, Ohyama K, Matsubayashi Y: Biochemical mapping of a ligand-binding domain within Arabidopsis BAM1 reveals diversified ligand recognition mechanisms of plant LRR-RKs. Plant J 2012, 70:845-854.

15. Jewaria PK, Hara T, Tanaka H, Kondo T, Betsuyaku S, Sawa S, Sakagami Y, Aimoto S, Kakimoto T: Differential effects of the peptides stomagen, EPF1 and EPF2 on activation of MAP kinase MPK6 and SPCH proteins level. Plant Cell Physiol 2013, 54:1253-1262.

16. Lee JS, Kuroha T, Hnilova M, Khatayevich D, Kanaoka MM, McAbee JM, Sarikaya M, Tamerler C, Torii KU: Direct interaction of ligand-receptor pairs specifying 
stomatal patterning. Genes Dev 2012, 26:126-136.

The authors examined peptide-receptor combinations and interreceptor interactions involved in stomatal formation. They clearly distinguished specific functions between ERF1-ERL1 and ERF2-ER pairs, using the kinase-dead receptors to overcome functional redundancy.

17. Uchida N, Tasaka M: Regulation of plant vascular stem cells by endodermis-derived EPFL-family peptide hormones and phloem expressed ERECTA-family receptor kinases. J Exp Bot 2013, 64:5335-5343.

18. Uchida N, Lee JS, Horst RJ, Lai H-H, Kajita R, Kakimoto T, Tasaka M, Torii KU: Regulation of inflorescence architecture by intertissue layer ligand-receptor communication between endodermis and phloem. Proc Natl Acad Sci U S A 2012, 109:6337-6342.

19. Lee JS, Torii KU: A tale of two systems: peptide ligand-receptor pairs in plant development. Cold Spring Harb Symp Quant Biol 2012, 77:83-89.

20. Kondo Y, Hirakawa Y, Kieber JJ, Fukuda H: CLE peptides can negatively regulate protoxylem vessel formation via cytokinin signaling. Plant Cell Physiol 2011, 52:37-48. 
21. Kim T-W, Michniewicz M, Bergmann DC, Wang Z-Y: Brassinosteroid regulates stomatal development by GSK3-mediated inhibition of a MAPK pathway. Nature 2012, 482:419-422.

22. Gudesblat GE, Schneider-Pizoń J, Betti C, Mayerhofer J, Vanhoutte I, van Dongen W, Boeren S, Zhiponova M, de Vries S, Jonak C et al.: SPEECHLESS integrates brassinosteroid and stomata signalling pathways. Nat Cell Biol 2012, 14:548-554.

23. Endo S, Shinohara H, Matsubayashi Y, Fukuda H: A novel pollen-pistil interaction conferring high-temperature tolerance during reproduction via CLE45 signaling. Curr Biol 23:1670-1676.

This study demonstrated that CLE45 peptide is induced by high temperature stress in female tissues and contributes to stable seed production by protecting pollen performance against high temperature, indicating a novel function of CLE peptides in mediating environmental stimuli into cell growth.

24. Okamoto S, Shinohara H, Mori T, Matsubayashi Y, Kawaguchi, M: Root-derived CLE glycopeptides control nodulation by direct binding to HAR1 receptor kinase. Nat Commun 2013, 4:2191. 
This study demonstrated that LjCLE-RS2 peptide was the root-to-shoot signal through xylem sap in autoregulation of nodulation. Mature LjCLE-RS2 peptide was identified as an arabinosylated form and shown to bind to HAR1. It was the first clear identification of such long-distance peptide signaling in plants.

25. Zipfel C: Combined roles of ethylene and endogenous peptides in regulating plant immunity and growth. Proc Natl Acad Sci U S A 2013, 110:5748-5749.

26. Liu Z, Wu Y, Yang F, Zhang Y, Chen S, Xie Q, Tian X, Zhou J-M: BIK1 interacts with PEPRs to mediate ethylene-induced immunity. Proc Natl Acad Sci U S A 2013, 110:6205-6210.

27. Tintor N, Ross A, Kanehara K, Yamada K, Fan L, Kemmerling B, Nürnberger T, Tsuda K, Saijo Y: Layered pattern receptor signaling via ethylene and endogenous elicitor peptides during Arabidopsis immunity to bacterial infection. Proc Natl Acad Sci U S A 2013, 110:6211-6216.

28. Igarashi D, Tsuda K, Katagiri F: The peptide growth factor, phytosulfokine, attenuates pattern-triggered immunity. Plant J 2012, 71:194-204.

29. Mosher S, Seybold H, Rodriguez P, Stahl M, Davies KA, Dayaratne S, Morillo SA, 
Wierzba M, Favery B, Keller $\mathrm{H}$ et al.: The tyrosine-sulfated peptide receptors PSKR1 and PSY1R modify the immunity of Arabidopsis to biotrophic and necrotrophic pathogens in antagonistic manner. Plant J 2013, 73:469-482.

30. Hirakawa Y, Shinohara H, Kondo Y, Inoue A, Nakanomyo I, Ogawa M, Sawa S, Ohashi-Ito K, Matsubayashi Y, Fukuda H: Non-cell-autonomous control of vascular stem cell fate by a CLE peptide/receptor system. Proc Natl Acad Sci U $S$ A 2008, 105:15208-15213.

31. Hobe M, Müller R, Grünewald M, Brand U, Simon R: Loss of CLE40, a protein functionally equivalent to the stem cell restricting signal CLV3, enhances root waving in Arabidopsis. Dev Genes Evol 2003, 213:371-381.

32. Bishopp A, Help H, El-Showk S, Weijers D, Sheres B, Friml J, Benková E, Mähönen AP, Helariutta Y: A mutually inhibitory interaction between auxin and cytokinin specifies vascular pattern in roots. Curr Biol 2011, 21:917-926.

33. Saidi Y, Hearn TJ, Coates JC: Function and evolution of 'green' GSK3/Shaggy-like kinases. Trends Plant Sci 2012, 17:39-41.

34. Torii KU: Mix-and-match: ligand-receptor pairs in stomatal development and beyond. Trends Plant Sci 2012, 17:711-719. 
35. Clouse SD: Brassinosteroids. The Arabidopsis book 2011, 9:e0151.

36. Depuydt S, Rodriguez-Villalon A, Santuari L, Wyser-Remili C, Ragni L, Hardtke S: Suppression of Arabidopsis protophloem differentiation and root meristem growth by CLE45 requires the receptor-like kinase BAM3. Proc Natl Acad Sci U S A 2013, 110:7074-7079.

37. Ogawa M, Shinohara H, Sakagami Y, Matsubayashi Y: Arabidopsis CLV3 peptide directly binds CLV1 ectodomain. Science 2008, 319:294.

38. Funayama-Noguchi S, Noguchi K, Yoshida C, Kawaguchi M: Two CLE genes are induced by phosphate in roots of Lotus japonicus. J Plant Res 2011, 124:155-163.

39. Miyazawa H, Oka-Kira E, Sato N, Takahashi H, Wu G-J, Sato S, Hayashi M, Betsuyaku S, Nakazono M, Tabata S et al.: The receptor-like kinase KLAVIER mediates systemic regulation of nodulation and non-symbiotic shoot development in Lotus japonicus. Development 2010, 137:4317-4325.

40. Okamoto S, Ohnishi E, Sato S, Takahashi H, Nakazono M, Tabata S, Kawaguchi M: Nod factor/nitrate-induced genes that drive HAR1-mediated systemic 
regulation of nodulation. Plant Cell Physiol 2009, 50:67-77.

41. Bouguyon E, Gojon A, Nacry P: Nitrate sensing and signaling in plants. Semin Cell Dev Biol 23:648-654.

42. Haruta M, Sabat G, Stecker K, Minkoff BB, Sussman MR: A peptide hormone and its receptor protein kinase regulate plant cell expansion. Science 2014, 343:408-411.

This study identified changes in the phosphorylation state of FER, calcium dependent protein kinase 9, $\mathrm{H}^{+}$-ATPase 2, PEN3/ABCG36 transporter and ERULUS protein kinase by the addition of RAFL peptide. Mass spectrometry-based quantitative phosphoproteomic profiling proved to be a powerful approach to reveal peptidereceptor system components.

43. Song X-F, Guo P, Ren S-C, Xu T-T, Liu C-M: Antagonistic peptide technology for functional dissection of CLV3/ESR genes in Arabidopsis. Plant Physiol 2013, 161:1076-1085.

44. Nagano AJ, Sato Y, Mihara M, Antonio BA, Motoyama R, Itoh H, Nagamura Y, Izawa T: Deciphering and prediction of transcriptome dynamics under fluctuating field conditions. Cell 2012, 151:1358-1369. 
45. Guo Y, Han L, Hymes M, Denver R, Clark SE: CLAVATA2 forms a distinct CLE-binding receptor complex regulating Arabidopsis stem cell specification. Plant J 2010, 63:889-900.

46. Kinoshita A, Betsuyaku S, Osakabe Y, Mizuno S, Nagawa S, Stahl Y, Simon R, Yamaguchi-Shinozaki K, Fukuda H, Sawa S: RPK2 is an essential receptor-like kinase that transmits the CLV3 signal in Arabidopsis. Development 2010, 137:3911-3920.

47. Suzaki T, Toriba T, Fujimoto M, Tsutsumi N, Kitano H, Hirano H-Y: Conservation and diversification of meristem maintenance mechanism in Oryza sativa: function of the FLORAL ORGAN NUMBER2 gene. Plant Cell Physiol 2006, 47:1591-1602.

48. Mortier V, Den Herder G, Whitford R, Van de Velde W, Rombauts S, D'haeseleer K, Holsters M, Goormachtig S: CLE peptides control Medicago truncatula nodulation locally and systemically. Plant Physiol 2010, 153:222-237.

49. Reid DE, Ferguson BJ, Gresshoff PM: Inoculation- and nitrate-induced CLE peptides of soybean control NARK-dependent nodule formation. Mol Plant Microbe Interact 2011, 24:606-618. 
50. Matsubayashi Y, Ogawa M, Morita A, Sakagami Y: An LRR receptor kinase involved in perception of a peptide plant hormone, phytosulfokine. Science 2002, 296:1470-1472.

51. Amano Y, Tsubouchi H, Shinohara H, Ogawa M, Matsubayashi Y:

Tyrosine-sulfated glycopeptide involved in cellular proliferation and expansion in Arabidopsis. Proc Natl Acad Sci U S A 2007, 104:18333-18338.

52. Stenvik G-E, Tandstad NM, Guo Y, Shi C-L, Kristiansen W, Holmgren A, Clark SE, Aalen RB, Butenko MA: The EPIP peptide of INFLORESCENCE DEFFICIENT IN ABSCISSION is sufficient to induce abscission in Arabidopsis through the receptor-like kinase HAESA and HAESA-LIKE2. Plant Cell 2008, 20:1805-1817.

53. Takayama S, Shimosato H, Shiba H, Funato M, Che F-S, Watanabe M, Iwano M, Isogai A: Direct ligand-receptor complex interaction controls Brassica self-incompatibility. Nature 2001, 413:534-538.

54. Jia G, Liu X, Owen HA, Zhao D: Signaling of cell fate determination by the TPD1 small proteins and EMS1 receptor kinase. Proc Natl Acad Sci U S A 2008, 105:2220-2225. 
(a)

Peptide ligands

Transmembrane receptors

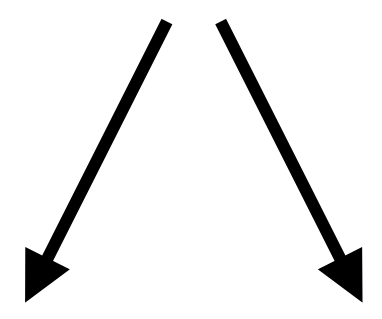

Developmental events (b)

(c)

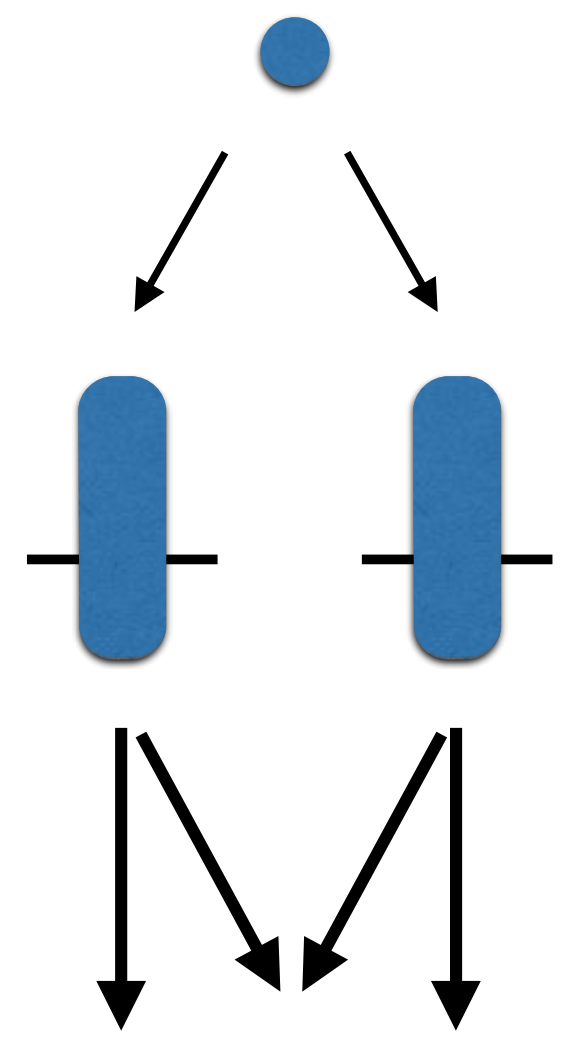

C D E
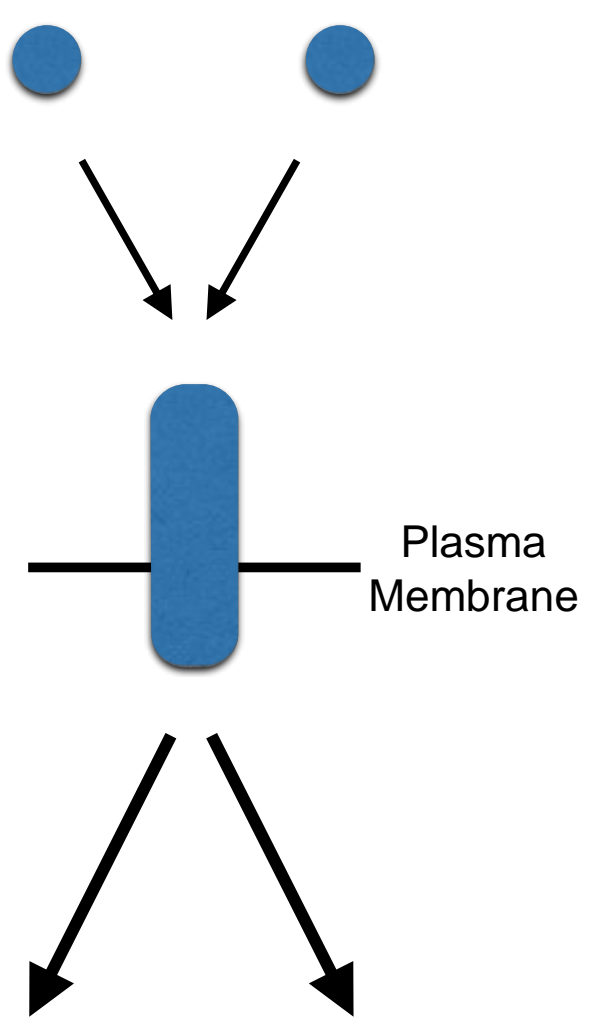

F

G 


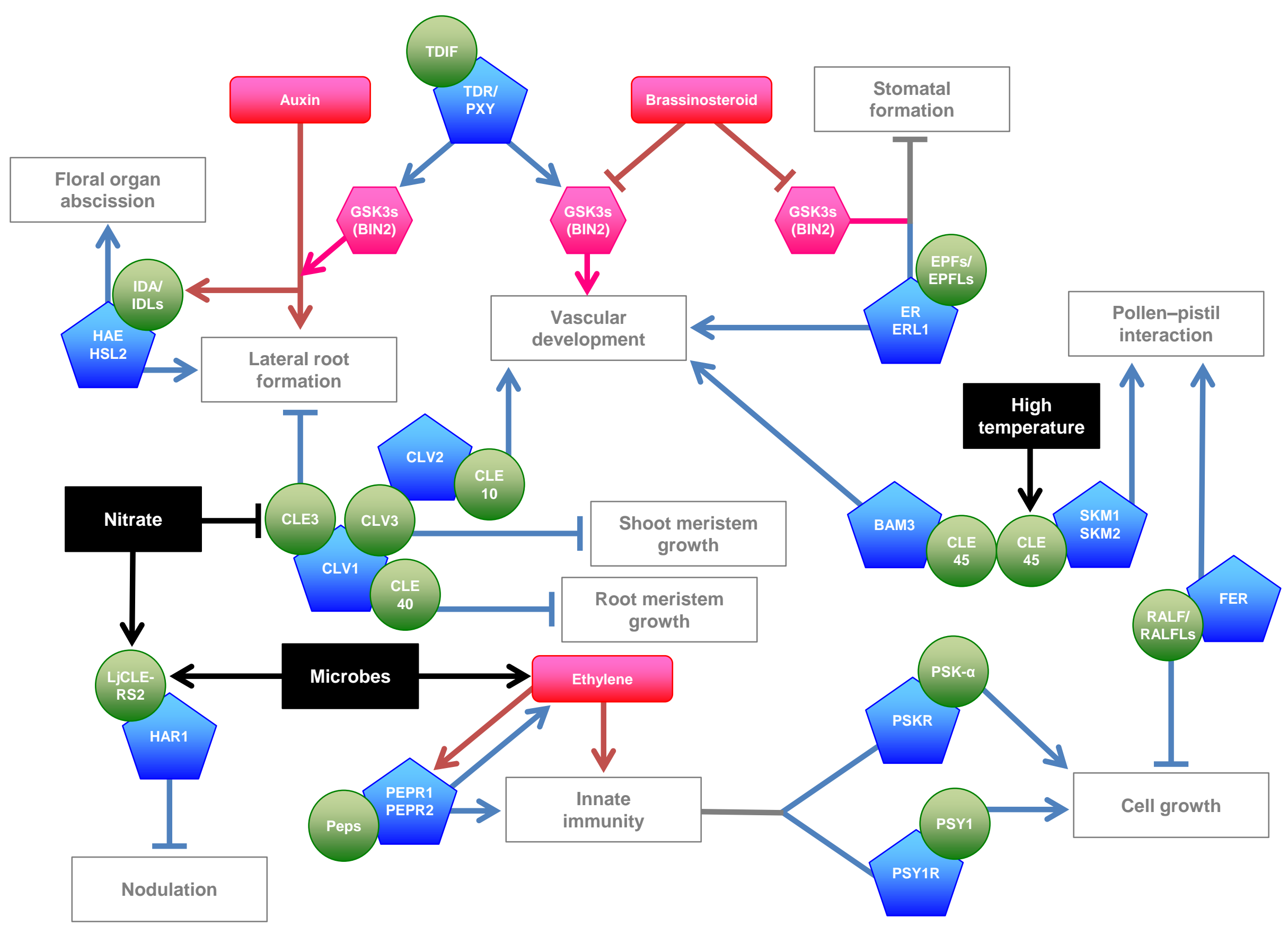

Figure 2 